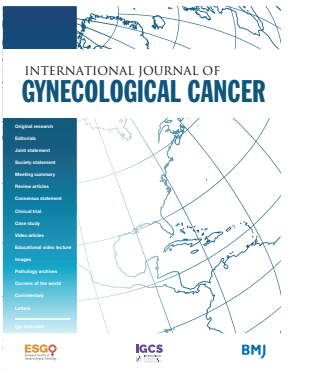

For numbered affiliations see end of article.

Correspondence to Dr Katharine McKinley Esselen, Department of Obstetrics and Gynecology, Beth Israel Deaconess Medical Center, Boston, MA 02215, USA; kesselen@bidmc.harvard.edu

Received 29 January 2021 Revised 26 March 2021 Accepted 30 March 2021 Published Online First 15 April 2021

\section{SLinked}

- http://dx.doi.org/10.1136/ ijgc-2021-002701

Check for updates

(c) IGCS and ESGO 2021. № commercial re-use. See rights and permissions. Published by BMJ.

To cite: Esselen KMcK, Gompers A, Hacker MR, et al. Int J Gynecol Cancer 2021;31:801-806.

\title{
Evaluating meaningful levels of financial toxicity in gynecologic cancers
}

\author{
Katharine McKinley Esselen, ${ }^{1,2}$ Annika Gompers, ${ }^{1}$ Michele R Hacker, ${ }^{1,2}$ Sara Bouberhan, ${ }^{3}$ \\ Meghan Shea, ${ }^{4}$ Sarah S Summerlin, ${ }^{5}$ Lindsay R Rucker, ${ }^{6}$ Warner K Huh, ${ }^{6}$ Maria Pisu, ${ }^{7}$ \\ Margaret I Liang ${ }^{6}$ \\ HIGHLIGHTS \\ - Nearly half of respondents reported moderate financial toxicity (COST <26), of which a third was severe $($ COST $<14)$ \\ - Economic cost-coping strategies were used by patients with moderate or severe financial toxicity \\ - Behavioral cost-coping strategies (medication non-compliance) were used by patients with severe financial toxicity
}

\section{ABSTRACT}

Objective The Comprehensive Score for Financial Toxicity (COST) is a validated instrument measuring the economic burden experienced by patients with cancer. We evaluated the frequency of financial toxicity at different COST levels and stratified risk factors and associations with cost-coping strategies by financial toxicity severity.

Methods We analyzed previously collected survey data of gynecologic oncology patients from two tertiary care institutions. Both surveys included the COST tool and questions assessing economic and behavioral cost-coping strategies. We adapted a proposed grading scale to define three groups: no/mild, moderate, and severe financial toxicity and used $\chi^{2}$, Fisher's exact test, and Wilcoxon rank sum test to compare groups. We used Poisson regression to calculate crude and adjusted risk ratios for cost-coping strategies, comparing patients with moderate or severe to no/mild financial toxicity.

Results Among 308 patients, $14.9 \%$ had severe, $32.1 \%$ had moderate, and $52.9 \%$ had no/mild financial toxicity. Younger age, non-white race, lower education, unemployment, lower income, use of systemic therapy, and shorter time since diagnosis were associated with worse financial toxicity (all $p<0.05$ ). Respondents with moderate or severe financial toxicity were significantly more likely to use economic cost-coping strategies such as changing spending habits (adjusted risk ratio (aRR) 2.7, $95 \% \mathrm{Cl} 1.8$ to 4.0 moderate; aRR $3.6,95 \% \mathrm{Cl} 2.4$ to 5.4 severe) and borrowing money (aRR $5.5,95 \% \mathrm{Cl} 1.8$ to 16.5 moderate; aRR $12.7,95 \% \mathrm{Cl} 4.3$ to 37.1 severe). Those with severe financial toxicity also had a significantly higher risk of behavioral cost-coping through medication noncompliance (aRR 4.6, 95\% $\mathrm{Cl} 1.2$ to 18.1).

Conclusions Among a geographically diverse cohort of gynecologic oncology patients, nearly half reported financial toxicity (COST <26), which was associated with economic cost-coping strategies. In those $14.9 \%$ of patients reporting severe financial toxicity $($ COST <14) there was also an increased risk of medication noncompliance, which may lead to worse health outcomes in this group.

\section{INTRODUCTION}

'Financial toxicity' describes the financial hardship and associated distress that patients with cancer experience due to the costs of care. ${ }^{1}$ It is estimated that approximately $40-70 \%$ of patients with cancer experience financial toxicity, which has been assessed using various objective (out of pocket costs, lost productivity, debt, or bankruptcy) and subjective measures (distress). ${ }^{2-4}$ One of the most widely used instruments to measure financial toxicity is the Comprehensive Score for Financial Toxicity (COST), a validated 11-item tool that measures financial distress as it relates to cancer diagnosis and treatment. ${ }^{56}$ Various thresholds for financial toxicity have been proposed using the COST score, often based on the median or percentile within discrete patient cohorts. ${ }^{7-9}$ A system proposed by the creators of the COST tool used effect sizes for quality of life scores to develop financial toxicity grades (grades 0-3) using COST scores. The grading system was further validated based on the odds of patients declaring bankruptcy within each group. ${ }^{9}$ Currently, there are limited data on what levels of financial toxicity measured by COST are linked to costcoping strategies such as economic behavior change and non-compliance with medications, which can lead to clinically meaningful worse health outcomes. ${ }^{78}$

There have been two single institution studies examining financial toxicity using the COST tool in patients with gynecologic cancer, which found that $40-50 \%$ of patients experience financial toxicity. To broaden our understanding of financial toxicity in gynecologic oncology, we combined data from these single institutional series to create a more diverse cohort of patients. First, we evaluated the frequency of financial toxicity at different COST levels and associated risk factors. Second, we measured the association of financial toxicity with meaningful cost-coping strategies, including economic behavior changes and medication non-compliance, stratified by proposed levels of financial toxicity severity. 


\section{Original research}

\section{METHODS}

\section{Study Population}

Institutional Review Board approval was obtained to conduct a multi-institutional analysis of previously collected survey data from Beth Israel Deaconess Medical Center (BIDMC) from 0ctober 2017 to March 2018 and University of Alabama at Birmingham (UAB) from April 2018 to January $2019 .{ }^{78}$ Informed consent was obtained from all subjects. The initial survey studies conducted at BIDMC and UAB have been previously described. ${ }^{78}$ Briefly, patients at BIDMC were women presenting to a gynecologic oncology practice at any point in treatment, including during active therapy or surveillance. Patients at UAB were women starting a new line of therapy for new or recurrent gynecologic cancer within the last 8 weeks. At BIDMC, patients with benign and pre-cancerous diagnoses were also included in the survey; however, these patients were excluded from the current analysis.

\section{Main Outcomes and Covariates}

Financial toxicity was measured by the 11-item COST tool. ${ }^{5}$ The COST score can range from 0 to 44 with lower scores indicating more severe financial toxicity. We excluded respondents who did not complete at least six items based on scoring guidelines. We adapted a financial toxicity grading scale previously proposed by the creators of the COST tool to define three levels: no/mild (COST $\geq 26$ ), moderate (COST 14-25), and severe financial toxicity (COST $0-13)^{9}$

Economic cost-coping strategies included changing spending habits or borrowing money. Changing spending habits was measured by participant responses to the questions: "Have you spent less on basic goods or leisure activities?" (BIDMC) and "Due to your cancer diagnosis, have you had to change your spending habits?" (UAB). Borrowing money was measured by participant responses to the questions "Have you borrowed money from friends, or family, or the bank?" (BIDMC) and "Due to your cancer diagnosis, have you had to borrow money?" (UAB). Behavioral costcoping strategies, which were collectively referred to as medication non-compliance, were measured by participant responses to the questions: "Have you delayed or avoided buying medication?" (BIDMC) and "Have you not taken medications as instructed or not refilled meds?" (UAB).

Patient and disease characteristics were abstracted from the medical record. Patient characteristics included age, race/ethnicity, partnership status, highest education level, employment status, health insurance, and household income. Disease characteristics included type of gynecologic cancer diagnosis, months since diagnosis, and history of prior treatment (any surgery, radiation, systemic treatment, or hormonal treatment).

\section{Statistical Analysis}

We compared demographic and disease characteristics between institutions and financial toxicity groups using $\chi^{2}$ or Fisher's exact test for categorical variables and Wilcoxon rank sum test for continuous variables. We used Poisson regression to calculate risk ratios (RR) for cost-coping strategies comparing moderate or severe financial toxicity groups with no/mild financial toxicity, adjusting for income and insurance type (aRR).

\section{RESULTS}

Out of 240 patients surveyed at BIDMC and 121 surveyed at UAB, a total of 308 respondents met the inclusion criteria for this multiinstitutional study. Patient characteristics of these study participants are stratified by institution in Table 1. There was no significant difference in severity of financial toxicity based on institution $(p=0.17)$ (Table 2). However, BIDMC respondents had a higher median COST score (28; IQR 21-36) than UAB respondents (24; IQR 17-31; $p=0.002$ ) (Table 1). Important demographic differences were noted between institutions and are summarized in Table 1. There was a higher proportion of black respondents $(27 \%$ vs $5 \%$, $\mathrm{p}<0.001)$ and a lower proportion of Hispanic $(0 \%$ vs $4 \%)$ and white $(71 \%$ vs $84 \%)$ respondents $(p<0.001)$ at UAB compared with BIDMC. Median household income was $\$ 87500$ (IQR \$37 599-\$100 000 ) at BIDMC compared with $\$ 40000$ (\$20 000-\$70 000) at UAB $(p<0.001)$. Notably, there were also differences in education and employment status with BIDMC respondents more likely to have a bachelor's degree or more ( $63 \%$ vs $33 \%$ ) and to be employed ( $46 \%$ vs $27 \%$ ), whereas $U A B$ respondents were more likely to be retired $(54 \%$ vs $34 \%$ ) (all $p<0.05)$. There were no significant differences in age or partnership status. With regard to clinical factors, patients surveyed at $U A B$ were more recently diagnosed than patients at BIDMC (7 months (IQR 2-29) vs 28 months (IQR 12-59)) ( $<<0.001)$, and all received systemic therapy compared with only $45 \%$ of BIDMC respondents. There were no significant differences in type of gynecologic cancer diagnosis or use of surgery, radiation, or hormonal therapies (all $p>0.05$ ).

Patient characteristics of study participants stratified by financial toxicity level are presented in Table 2. In our cohort, 14.9\% (46/308) had severe, 32.1\% (99/308) had moderate, and 52.9\% (163/308) had no/mild financial toxicity. When stratified by level of toxicity, the median age was significantly lower for more severe levels of financial toxicity: 63 years (IQR 56-70) in the no/mild financial toxicity group, 60 years (IQR 49-68) in the moderate financial toxicity group, and 54 years (IQR 50-61) in the severe financial toxicity group $(p<0.001)$. Increasing proportions of non-white race $(p=0.003)$ and lower levels of educational attainment $(p=0.03)$ were seen in patients with moderate and severe financial toxicity compared with no/mild financial toxicity. Median household income in the severe financial toxicity group (median $\$ 37500$ ) and moderate financial toxicity group (median $\$ 37500$ ) were significantly lower than in the no/mild toxicity group (median $\$ 87500$ ). Employment status $(p<0.001)$ and insurance type $(p<0.001)$ were also associated with severity of financial toxicity. Type of gynecologic cancer diagnosis was not associated with severity of toxicity $(p=0.24)$; however, shorter time since diagnosis, undergoing cancer surgery, and use of any systemic therapy were associated with level of financial toxicity (all $p<0.05$ ).

Respondents with severe financial toxicity were 4.6 times $(95 \% \mathrm{Cl} 1.2$ to 18.1$)$ significantly more likely to report medication non-compliance than those with no/mild financial toxicity after adjusting for income and insurance type. They also were significantly more likely to report changing spending habits (aRR 3.6, $95 \% \mathrm{Cl} 2.4$ to 5.4 ) and borrowing money (aRR $12.7,95 \% \mathrm{Cl} 4.3$ to $37.1)$ due to the costs of cancer care. Women reporting moderate financial toxicity, however, were not more likely to report medication non-compliance than those with no/mild financial toxicity (aRR 
Table 1 Demographic and disease characteristics by institution

\begin{tabular}{|c|c|c|c|}
\hline & $\begin{array}{l}\text { BIDMC } \\
(\mathrm{n}=187)\end{array}$ & $\begin{array}{l}\text { UAB } \\
(n=121)\end{array}$ & $P$ value \\
\hline COST score & $28(21-36)$ & $24(17-31)$ & 0.002 \\
\hline Age & $62(53-69)$ & $60(52-67)$ & 0.29 \\
\hline \multicolumn{4}{|l|}{ Race/ethnicity } \\
\hline White/Caucasian & $158(84)$ & $86(71)$ & $<0.001$ \\
\hline $\begin{array}{l}\text { Black/African } \\
\text { American }\end{array}$ & $10(5)$ & $33(27)$ & \\
\hline $\begin{array}{l}\text { Hispanic/Latina/ } \\
\text { Spanish }\end{array}$ & $7(4)$ & $0(0)$ & \\
\hline Other/missing & $12(6)$ & $2(2)$ & \\
\hline \multicolumn{4}{|l|}{ Partnership status } \\
\hline Married or partnered & $115(62)$ & $65(54)$ & 0.19 \\
\hline $\begin{array}{l}\text { Single, divorced, or } \\
\text { widowed }\end{array}$ & $70(37)$ & $56(46)$ & \\
\hline Missing & $2(1)$ & $0(0)$ & \\
\hline \multicolumn{4}{|l|}{ Education level } \\
\hline High school or less & $21(11)$ & $33(27)$ & $<0.001$ \\
\hline $\begin{array}{l}\text { Completed some } \\
\text { college }\end{array}$ & $19(10)$ & $48(40)$ & \\
\hline $\begin{array}{l}\text { Bachelor's degree or } \\
\text { more }\end{array}$ & $117(63)$ & $40(33)$ & \\
\hline Missing & $30(16)$ & $0(0)$ & \\
\hline \multicolumn{4}{|l|}{ Employment } \\
\hline Employed & $86(46)$ & $33(27)$ & 0.002 \\
\hline Not employed & $30(16)$ & $15(12)$ & \\
\hline Retired & $65(35)$ & $65(54)$ & \\
\hline Missing & $6(3)$ & $8(7)$ & \\
\hline \multicolumn{4}{|l|}{ Health insurance } \\
\hline Private & $99(53)$ & $51(42)$ & $<0.001$ \\
\hline $\begin{array}{l}\text { Medicare with } \\
\text { supplement }\end{array}$ & $44(24)$ & $39(32)$ & \\
\hline $\begin{array}{l}\text { Medicare without } \\
\text { supplement/military* }\end{array}$ & $23(12)$ & $12(10)$ & \\
\hline Medicaid & $21(11)$ & $10(8)$ & \\
\hline Uninsured & $0(0)$ & $9(7)$ & \\
\hline Household income (\$) & $\begin{array}{l}87.5 \mathrm{~K} \\
(37.5 \mathrm{~K}- \\
100 \mathrm{~K})\end{array}$ & $\begin{array}{l}40 \mathrm{~K} \\
(20 \mathrm{~K}-70 \mathrm{~K})\end{array}$ & $<0.001$ \\
\hline \multicolumn{4}{|l|}{ Diagnosis } \\
\hline Ovarian & $82(44)$ & $64(53)$ & 0.08 \\
\hline Uterine & $79(42)$ & $34(28)$ & \\
\hline Cervical & $22(12)$ & $18(15)$ & \\
\hline Vulvar/vaginal & $4(2)$ & $5(4)$ & \\
\hline Months since diagnosis & $28(12-59)$ & $7(2-29)$ & $<0.001$ \\
\hline \multicolumn{4}{|l|}{ Treatment $†$} \\
\hline Surgery & $167(89)$ & $99(82)$ & 0.06 \\
\hline Radiation & $38(20)$ & $30(25)$ & 0.36 \\
\hline
\end{tabular}

Table 1 Continued

\begin{tabular}{lccc}
\hline & $\begin{array}{l}\text { BIDMC } \\
(\mathbf{n}=187)\end{array}$ & $\begin{array}{l}\text { UAB } \\
(\mathbf{n}=121)\end{array}$ & P value \\
\hline Systemic treatment & $85(45)$ & $121(100)$ & $<0.001$ \\
Hormonal treatment & $2(1)$ & $5(4)$ & 0.12 \\
\hline
\end{tabular}

Data are shown as median (IQR) or number (\%).

*Two respondents had military insurance.

$\dagger$ Treatment categories are not mutually exclusive.

BIDMC, Beth Israel Deaconess Medical Center; COST,

Comprehensive Score for Financial Toxicity; K, 1000; UAB,

University of Alabama at Birmingham.

$1.1,95 \% \mathrm{Cl} 0.2$ to 4.7$)$. Similar to patients with severe financial toxicity, patients with moderate financial toxicity did have a significantly higher risk of changing spending habits (aRR $2.7,95 \% \mathrm{Cl}$ 1.8 to 4.0 ) and borrowing money (aRR $5.5,95 \% \mathrm{Cl} 1.8$ to 16.5 ), although the risk was lower (Table 3).

\section{DISCUSSION}

\section{Summary of Main Results}

Among a geographically diverse cohort of gynecologic oncology patients, nearly half reported at least moderate financial toxicity using COST score $<26$, of whom a third reported severe financial toxicity using COST score $<14$. Financial toxicity at moderate and severe levels was associated with utilization of cost-coping strategies, particularly economic behavior changes, whereas medication non-compliance was only significantly used by those with severe financial toxicity. These findings suggest that cost-coping strategies vary based on the financial toxicity level and can be used in clinical practice to proactively direct financial resources and counseling to patients.

\section{Results in the Context of Published Literature}

Nearly $50 \%$ of surveyed patients reported financial toxicity, which approximates or exceeds estimates of financial burden in broader cancer populations. ${ }^{3410}$ Within our multi-institutional patient cohort, we also confirmed previously described risk factors for financial toxicity including younger age, lower income, insurance status, and need for systemic therapy. While many of these factors are not modifiable, they can be used to identify patients at increased risk for financial toxicity. ${ }^{347810}$ In two systematic reviews of financial toxicity that included 25 and 50 studies, respectively, younger age was associated with higher financial toxicity. ${ }^{34}$ Younger age is a risk factor that can be readily accessed and likely contributes to financial toxicity for a variety of reasons, such as younger patients are not eligible for Medicare, diagnosis and treatment may impact their ability to work, and they have had less earning years to accumulate a financial safety net. In our current analysis, increasing financial toxicity is associated with decreasing median age (Table 2).

\section{Strengths and Weaknesses}

We sought to understand financial toxicity in a more diverse population by combining data from two very geographically distinct institutions to provide a more comprehensive understanding of how patients with gynecologic cancer are affected by financial distress. Not surprisingly, there were many differences in the 
Table 2 Demographic and disease characteristics by financial toxicity level

\begin{tabular}{|c|c|c|c|c|c|}
\hline Characteristic & $\begin{array}{l}\text { All } \\
\text { respondents } \\
\mathrm{n}=308\end{array}$ & $\begin{array}{l}\text { Severe financial } \\
\text { toxicity (COST } \\
0-13) n=46\end{array}$ & $\begin{array}{l}\text { Moderate financial } \\
\text { toxicity (COST } \\
\text { 14-25) } n=99\end{array}$ & $\begin{array}{l}\text { No/mild financial } \\
\text { toxicity (COST } \geq 26) \\
n=163\end{array}$ & $P$ value \\
\hline Location & & & & & 0.17 \\
\hline BIDMC & $187(61)$ & $26(57)$ & $54(55)$ & $107(66)$ & \\
\hline UAB & $121(39)$ & $20(43)$ & $45(45)$ & $56(34)$ & \\
\hline COST score & $26(19-34)$ & $9(6-11)$ & $21(18-23)$ & $33(30-38)$ & $<0.001$ \\
\hline Age & $61(52-69)$ & $54(50-61)$ & $60(49-68)$ & $63(56-70)$ & $<0.001$ \\
\hline \multicolumn{6}{|l|}{ Race/ethnicity } \\
\hline White/Caucasian & $244(79)$ & $30(65)$ & $73(74)$ & $141(87)$ & 0.003 \\
\hline Black/African American & $43(14)$ & $8(17)$ & $20(20)$ & $15(9)$ & \\
\hline $\begin{array}{l}\text { Hispanic/Latina/ } \\
\text { Spanish }\end{array}$ & $7(2)$ & $4(9)$ & $2(2)$ & $1(1)$ & \\
\hline Other/missing & $14(5)$ & $4(9)$ & $4(4)$ & $6(4)$ & \\
\hline \multicolumn{6}{|l|}{ Partnership status } \\
\hline Married or partnered & $180(58)$ & $23(50)$ & $52(53)$ & $105(64)$ & 0.15 \\
\hline $\begin{array}{l}\text { Single, divorced, or } \\
\text { widowed }\end{array}$ & $126(41)$ & $23(50)$ & $46(46)$ & $57(35)$ & \\
\hline Missing & $2(1)$ & $0(0)$ & $1(1)$ & $1(1)$ & \\
\hline \multicolumn{6}{|l|}{ Education level } \\
\hline High school or less & $54(18)$ & $10(22)$ & $25(25)$ & $19(12)$ & 0.03 \\
\hline Completed some college & $67(22)$ & $10(22)$ & $26(26)$ & $31(19)$ & \\
\hline Bachelor's degree or more & $157(51)$ & $22(48)$ & $38(38)$ & $97(60)$ & \\
\hline Missing & $30(10)$ & $4(9)$ & $10(10)$ & $16(10)$ & \\
\hline \multicolumn{6}{|l|}{ Employment } \\
\hline Employed & 119 (39) & $21(46)$ & $30(30)$ & $68(42)$ & $<0.001$ \\
\hline Not employed & $45(15)$ & $13(28)$ & $19(19)$ & $13(8)$ & \\
\hline Retired & $130(42)$ & $7(15)$ & $45(45)$ & $78(48)$ & \\
\hline Missing & $14(5)$ & $5(11)$ & $5(5)$ & $4(2)$ & \\
\hline \multicolumn{6}{|l|}{ Health insurance } \\
\hline Private & $150(49)$ & $21(46)$ & $41(41)$ & $88(54)$ & $<0.001$ \\
\hline Medicare with supplement & $83(27)$ & $4(9)$ & $23(23)$ & $56(34)$ & \\
\hline $\begin{array}{l}\text { Medicare without } \\
\text { supplement/military* }\end{array}$ & $35(11)$ & $6(13)$ & $14(14)$ & $15(9)$ & \\
\hline Medicaid & $31(10)$ & $9(20)$ & $19(19)$ & $3(2)$ & \\
\hline Uninsured & $9(3)$ & $6(13)$ & $2(2)$ & $1(1)$ & \\
\hline Household income (\$) & $\begin{array}{l}62.5 \mathrm{~K} \\
(30 \mathrm{~K}-100 \mathrm{~K})\end{array}$ & $\begin{array}{l}37.5 \mathrm{~K} \\
(20 \mathrm{~K}-62.5 \mathrm{~K})\end{array}$ & $\begin{array}{l}37.5 \mathrm{~K} \\
(30 \mathrm{~K}-70 \mathrm{~K})\end{array}$ & $\begin{array}{l}87.5 \mathrm{~K} \\
(50 \mathrm{~K}-100 \mathrm{~K})\end{array}$ & $<0.001$ \\
\hline \multicolumn{6}{|l|}{ Diagnosis } \\
\hline Ovarian & $146(47)$ & $22(48)$ & $46(46)$ & $78(48)$ & 0.24 \\
\hline Uterine & $113(37)$ & $13(28)$ & $34(34)$ & $66(40)$ & \\
\hline Cervical & $40(13)$ & $10(22)$ & $16(16)$ & $14(9)$ & \\
\hline Vulvar/vaginal & $9(3)$ & $1(2)$ & $3(3)$ & $5(3)$ & \\
\hline Months since diagnosis & $19(6-47)$ & $11(4-38)$ & $17(4-41)$ & $26(8-55)$ & 0.046 \\
\hline \multicolumn{6}{|l|}{ Treatment† } \\
\hline Surgery & $266(86)$ & $36(78)$ & $81(82)$ & $149(91)$ & 0.02 \\
\hline Radiation & $68(22)$ & $12(26)$ & $26(26)$ & 30 (18) & 0.26 \\
\hline
\end{tabular}


Table 2 Continued

\begin{tabular}{|c|c|c|c|c|c|}
\hline Characteristic & $\begin{array}{l}\text { All } \\
\text { respondents } \\
n=308\end{array}$ & $\begin{array}{l}\text { Severe financial } \\
\text { toxicity (COST } \\
0-13) n=46\end{array}$ & $\begin{array}{l}\text { Moderate financial } \\
\text { toxicity (COST } \\
14-25) n=99\end{array}$ & $\begin{array}{l}\text { No/mild financial } \\
\text { toxicity }(\text { COST } \geq 26) \\
n=163\end{array}$ & $P$ value \\
\hline Systemic treatment & $206(67)$ & $37(80)$ & $78(79)$ & $91(56)$ & $<0.001$ \\
\hline Hormonal treatment & $7(2)$ & $0(0)$ & $5(5)$ & $2(1)$ & 0.11 \\
\hline
\end{tabular}

Data are shown as median (IQR) or number (\%).

${ }^{*}$ Two respondents had military insurance.

†Treatment categories are not mutually exclusive.

BIDMC, Beth Israel Deaconess Medical Center; COST, Comprehensive Score for Financial Toxicity; K, 1000; UAB, University of Alabama at Birmingham.

demographic characteristics of the surveyed patients at each institution, including important risk factors for financial toxicity such as race, income, education, employment status, and insurance status. Despite these differences as well as lower median COST score at UAB compared with BIDMC, the distribution of financial toxicity levels was not significantly different at the two institutions. This suggests that, regardless of perceived risk factors, some of which are not routinely collected in the electronic health record (income, education, employment status), the COST score is a useful tool that can be broadly applied to identify gynecologic cancer patients with financial needs. Importantly, we also further assessed a proposed three-level grading system of the COST score and demonstrated that there are differences in the use of cost-coping strategies across these three groups. ${ }^{9}$

One of the weaknesses of our analysis is that it is a retrospective review of prospectively collected data with different inclusion criteria. At $U A B$, patients were surveyed who were actively undergoing systemic treatment whereas, at BIDMC, patients were surveyed who were on treatment and in surveillance regardless of type of treatment employed. These differences in methodology account for important differences in time since diagnosis and use of systemic therapy that were noted between the two cohorts. Further, the COST tool asks respondents to recall their experience over the last 7 days. As financial toxicity is likely dynamic over the course of a patient's illness, this study is limited by the cross-sectional administration of the survey to patients at various points in their disease trajectory. Finally, although this is a more geographically diverse cohort, it remains limited to two large academic tertiary care centers and may not be representative of other health systems or regions of the country.

\section{Implications for Practice and Future Research}

Cost-coping strategies varied based on the severity level of financial toxicity. Patients with severe financial toxicity ( $14.9 \%$ of our cohort) had a nearly five-fold increased risk of medication non-compliance. A systematic review of the financial burden in cancer care showed that those with an increased financial burden (measured as having higher financial distress, co-pays, or prescription costs) had 1.7 increased odds of cancer medication non-compliance $(95 \% \mathrm{Cl} 1.13$ to 2.56), ${ }^{3}$ while respondents in our study with either moderate or severe financial toxicity had a significantly increased risk of using economic cost-coping strategies. Our findings suggest that patients

Table 3 Risk of cost-coping strategies for respondents with moderate or severe financial toxicity compared with respondents with no/mild financial toxicity

\begin{tabular}{|c|c|c|c|c|c|c|}
\hline $\begin{array}{l}\text { Financial toxicity } \\
\text { level }\end{array}$ & $\mathbf{N}$ & $\begin{array}{l}\text { Cost-coping } \\
\text { strategy } \\
\text { N (\%) }\end{array}$ & $\begin{array}{l}\text { Crude risk ratio } \\
(95 \% \mathrm{Cl})\end{array}$ & $\begin{array}{l}\text { Risk ratio } \\
\text { adjusted for } \\
\text { income } \\
(95 \% \mathrm{Cl})\end{array}$ & $\begin{array}{l}\text { Risk ratio } \\
\text { adjusted for } \\
\text { insurance } \\
(95 \% \mathrm{Cl})\end{array}$ & $\begin{array}{l}\text { Risk ratio } \\
\text { adjusted for } \\
\text { income and } \\
\text { insurance } \\
(95 \% \mathrm{Cl})\end{array}$ \\
\hline \multicolumn{7}{|c|}{ Medication non-compliance } \\
\hline No/mild & 163 & $3(2)$ & Ref & Ref & Ref & Ref \\
\hline Moderate & 99 & $3(3)$ & $1.6(0.3$ to 8.0$)$ & $0.9(0.2$ to 4.3$)$ & $1.6(0.4$ to 7.0$)$ & $1.1(0.2$ to 4.7$)$ \\
\hline Severe & 46 & $8(17)$ & 9.4 (2.6 to 34.2$)$ & $4.2(1.1$ to 16.7$)$ & 9.2 (2.5 to 33.8$)$ & $4.6(1.2$ to 18.1$)$ \\
\hline \multicolumn{7}{|c|}{ Changed spending habits } \\
\hline No/mild & 163 & $29(18)$ & Ref & Ref & Ref & Ref \\
\hline Moderate & 99 & $53(54)$ & $3.0(2.1$ to 4.4$)$ & $2.6(1.7$ to 4.0$)$ & $3.0(2.1$ to 4.4$)$ & 2.7 (1.8 to 4.0$)$ \\
\hline Severe & 46 & $37(80)$ & 4.5 (3.2 to 6.5$)$ & 3.7 (2.5 to 5.6$)$ & 4.2 (2.9 to 6.2$)$ & $3.6(2.4$ to 5.4$)$ \\
\hline \multicolumn{7}{|l|}{ Borrowed money } \\
\hline No/mild & 163 & $4(2)$ & Ref & Ref & Ref & Ref \\
\hline Moderate & 99 & $21(21)$ & 8.6 (3.1 to 24.4$)$ & 5.6 (1.8 to 17.4$)$ & 8.4 (3.0 to 24.0$)$ & 5.5 (1.8 to 16.5$)$ \\
\hline Severe & 46 & $23(50)$ & 20.4 (7.4 to 55.9$)$ & $12.8(4.2$ to 38.9$)$ & 19.6 (6.8 to 56.3$)$ & 12.7 (4.3 to 37.1$)$ \\
\hline
\end{tabular}




\section{Original research}

with COST scores $<26$, particularly COST scores $<14$, should be identified and provided with resources necessary to avoid noncompliance with medications.

Future research should incorporate these COST levels, particularly COST $<14$, as a threshold for severe financial toxicity to study whether compliance with recommended care (dose intensity of therapy, treatment delays, or missed appointments) and clinical cancer outcomes (time to completion of therapy, survival) differ based on severity level of financial toxicity. In addition, future studies should evaluate whether financial toxicity occurs on a continuum where proactive efforts to address financial toxicity at more mild levels have the potential to avoid the development of more severe financial toxicity and thus worse cost-coping behaviors.

\section{CONCLUSIONS}

Financial toxicity (COST <26) affects nearly half of patients with gynecologic cancer and is associated with the use of economic cost-coping strategies. Further application of a severity scale showed that those reporting the most severe financial toxicity level (COST <14) are also at increased risk for use of behavioral costcoping strategies measured by medication non-compliance, which is particularly important to target as these types of coping behaviors may lead to worse health outcomes.

\author{
Author affiliations \\ ${ }^{1}$ Department of Obstetrics and Gynecology, Beth Israel Deaconess Medical Center, \\ Boston, Massachusetts, USA \\ ${ }^{2}$ Obstetrics, Gynecology and Reproductive Biology, Harvard Medical School, Boston, \\ Massachusetts, USA \\ ${ }^{3}$ Department of Hematology/Medical Oncology, Massachusetts General Hospital, \\ Boston, Massachusetts, USA \\ ${ }^{4}$ Department of Medicine, Beth Israel Deaconess Medical Center, Harvard Medical \\ School, Boston, Massachusetts, USA \\ ${ }^{5}$ School of Medicine, The University of Alabama, Birmingham, Alabama, USA \\ ${ }^{6}$ Department of Obstetrics and Gynecology, The University of Alabama, Birmingham, \\ Alabama, USA \\ ${ }^{7}$ Department of Internal Medicine, The University of Alabama, Birmingham, \\ Alabama, USA
}

Contributors KME: conceptualization, investigation, methodology, supervision, writing - original draft preparation. AG: formal analysis, writing - reviewing and editing. MRH: conceptualization, methodology, supervision, writing - reviewing and editing. SB: investigation, writing - reviewing and editing. MS: writing - reviewing and editing. SSS: investigation, writing - reviewing and editing. LRR: investigation, writing - reviewing and editing. WKH: writing - reviewing and editing. MP: methodology, supervision, writing - reviewing and editing. MIL: conceptualization, investigation, methodology, supervision, writing - original draft preparation.

Funding MIL was supported by a National Institute of Child and Human Development Women's Reproductive Health Research Career Development K-12 Grant (5K12HD001258) for this work. The Retention and Recruitment Shared Facility at O'Neal Comprehensive Cancer Center used to conduct the surveys at University of Alabama at Birmingham is supported by the Cancer Center Support Grant (P30CA013148). KME was supported by the Eleanor and Miles Shore 50th Anniversary Fellowship Program and Harvard Catalyst I The Harvard Clinical and Translational Science Center (National Center for Advancing Translational Sciences, National Institutes of Health Award UL 1TR002541) and financial contributions from Harvard University and its affiliated academic healthcare centers. The funding organizations had no role in the preparation, review, or approval of the manuscript.

Competing interests WKH reports personal fees from LICOR Biosciences, Altum outside the submitted work and serves on the Data and Safety Monitoring board for Inovio Pharmaceuticals.

Patient consent for publication Not required.

Provenance and peer review Not commissioned; externally peer reviewed.

Data availability statement Data are available upon reasonable request and with appropriate institutional review board approval.

\section{REFERENCES}

1 Zafar SY, McNeil RB, Thomas CM, et al. Population-based assessment of cancer survivors' financial burden and quality of life: a prospective cohort study. J Oncol Pract 2015;11:145-50.

2 Gordon LG, Merollini KMD, Lowe A, et al. A systematic review of financial toxicity among cancer survivors: we can't pay the co-pay. Patient 2017;10:295-309.

3 Smith GL, Lopez-Olivo MA, Advani PG, et al. Financial burdens of cancer treatment: a systematic review of risk factors and outcomes. J Natl Compr Canc Netw 2019;17:1184-92.

4 Altice CK, Banegas MP, Tucker-Seeley RD, et al. Financial hardships experienced by cancer survivors: a systematic review. J Nat/ Cancer Inst 2017;109:djw205.

5 de Souza JA, Yap BJ, Hlubocky FJ, et al. The development of a financial toxicity patient-reported outcome in cancer: the COST measure. Cancer 2014;120:3245-53.

6 de Souza JA, Yap BJ, Wroblewski K, et al. Measuring financial toxicity as a clinically relevant patient-reported outcome: the validation of the COmprehensive Score for financial Toxicity (COST). Cancer 2017;123:476-84.

7 Bouberhan S, Shea M, Kennedy A, et al. Financial toxicity in gynecologic oncology. Gynecol Oncol 2019;154:8-12.

8 Liang MI, Pisu M, Summerlin SS, et al. Extensive financial hardship among gynecologic cancer patients starting a new line of therapy. Gynecol Oncol 2020;156:271-7.

9 De Souza JA, Wroblewski K, Proussaloglou E, et al. Validation of a financial toxicity (FT) grading system. J Clin Oncol 2017;35:6615.

10 Carrera PM, Kantarjian HM, Blinder VS. The financial burden and distress of patients with cancer: understanding and stepping-up action on the financial toxicity of cancer treatment. CA Cancer J Clin 2018;68:153-65. 